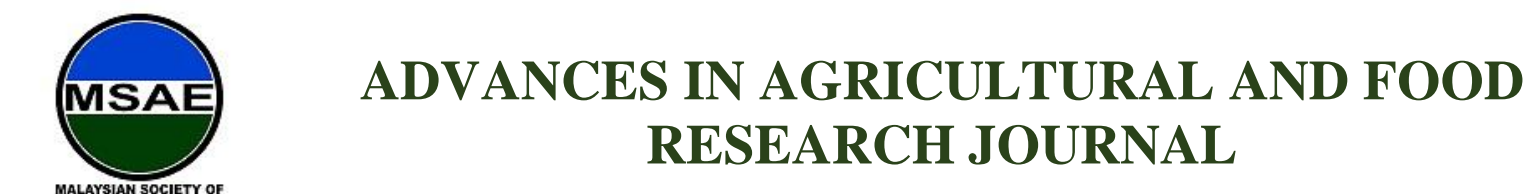

Original Research Article

\title{
Sweet Potato Peel Flour Applications in The Textural Quality of Waffle Ice Cream Cone and Other Food Products
}

\author{
Zanariah Mohd Dom ${ }^{1 *}$, Nurul Atikah Mohd Zulkeple Amin ${ }^{1}$, Roseliza Kadir Basha ${ }^{1}$ \\ ${ }^{1}$ Department of Process and Food Engineering, Faculty of Engineering, Universiti Putra Malaysia, 43400 \\ Serdang, Selangor, Malaysia \\ *Corresponding author: Zanariah Mat Dom, Department of Process and Food Engineering, Faculty of \\ Engineering, Universiti Putra Malaysia, 43400 Serdang, Selangor, Malaysia; nana@upm.edu.my
}

Abstract: Sweet potatoes are nutritious vegetables commonly grown in Malaysia. However, its beneficial skins are mostly peeled and thrown away. The sweet potato peel has a slightly bitter taste with its good nutritional food value in producing healthy food products. In this study, sweet potato peel flour (SPPF) is added to the existing wheat flour in the formulation of ice cream waffle cones. The amount of wheat flour added in the mixture depends on the SPPF amount added. Preliminary study on the content of protein, moisture, crude fiber, protein, carbohydrate and fat were conducted and determined. Then, the SPPF was added based on the formulation of $5 \%, 10 \%$ and $15 \%$ addition to the wheat flour at $95 \%, 90 \%$ and $85 \%$, respectively, in a batter mix formulation for the making of ice cream waffle cones. The control was made out of $100 \%$ wheat flour, in order to compare with the newly formulated ice cream waffle cones batter mixture. Substitution of SPPF has impacted the quality of waffle ice cream cone in regards to its physicochemical properties such as colour, odour, tensile strength and textural properties. As the results, waffle cones of SPPF had lower value of L*, $a^{*}$ and $b^{*}$, which turned darker than a controlled sample. The $5 \%$ formulation of sweet potato peel flour (SPPF) resulted to the highest crispiness of the waffle cones. Tensile strength of fiber materials in sweet potato peels flour became stable and balanced with the cone structure. Overall SPPF formulated waffle cones have passed the physical analysis and food applications' requirements. As the SPPF have high value in water holding capacity, it can contribute to other food applications.

Keywords: sweet potato; sweet potato peel flour; waffle; sweet potato peel waffle cones; food application

Received: $11^{\text {th }}$ November 2020

Citation: Mohd Dom Z, Mohd Zulkeple Amin NA, Kadir Basha R. Sweet potato peel flour applications in

Accepted: $12^{\text {th }}$ December 2020 the textural quality of waffle ice cream cone and other

Available Online: $30^{\text {th }}$ December 2020 food products. Adv Agri Food Res J 2020; 1(2): a0000150. https://doi.org/10.36877/aafrj.a0000150

\section{Introduction}

Sweet potato (Ipomoea batatas) is a dicotyledonous plant that belongs to morningglory family, Convolvulaceae. It is widely grown throughout the tropics and warm 
temperature regions of the world. It is very valuable because of its short growing period for 90 days to 120 days, which is important crop for the developing countries (Mohd Hanim et $a l ., 2014)$. Sweet potato is high in nutritional value including fiber, carbohydrate, vitamin C, vitamin $\mathrm{A}$ ( $\beta$-carotene) and protein, which are healthy nutrients needed by the human body.

In Malaysia, sweet potato ranks the second popular tuber crops next to cassava (Mohd Hanim et al., 2014). There are a few varieties of sweet potato available in Malaysia including Batang Merah, Senduduk Kulit Putih, Senduduk Kulit Merah, Mahsuri and VitAto (Mohamad Zahari et al., 2014). VitAto is an orange-flesh sweet potato and the latest sweet potato variety cultivated by the Malaysia Agricultural Research and Development Institute (MARDI) in June 2017. Research conducted by MARDI found out that the VitAto sweet potato is suitable to plant on the ground bris in the country. Most of the ground bris area involved the large-scale plantation in Kelantan and Terengganu (Hashim et al., 2019).

Back then, the sweet potato is very synonym to the Malay community as the main ingredients in making traditional kuih-muih such as cek mek molek, onde-onde, bingka and keria. But people today are less interested on Malay traditional desserts, since they are more interested on bakery products such as biscuits, muffins and cakes. To keep the value of sweet potato in the market, more initiatives should be considered in other optimal and potential usage of sweet potato apart from making local traditional desserts.

In producing sweet potato-based food products, the sweet potato peels are being peeled off and become a disposable waste especially for the stall and restaurant operators. The sweet potato peels are being disposed as municipal solid waste, which could increase the amount of rubbish to the environment. The global amount of sweet potato waste in 2011 accounted for about $7 \%$ of the entire crop (FAO, 2016). As the sweet potato peels also contain good health nutrition, it is useless if we do not use it wisely as it has the potential to be processed as a new health product. Converting sweet potato peel into flour is an alternative way to diversify the new product from the sweet potato peel and reduce the amount of sweet potato peel waste to be disposed by the stall and restaurant operators. This contributes greatly to increase the revenue of the farmers and increase the growth of Malaysian economy.

Sweet potato peels are edible and has good source of nutritious value, which is high in carbohydrate, protein and fiber that give various beneficial effects to human health such as the main source of energy and reducing diabetes. Sweet potato peel flour (SPPF) has been applied in the food industry as a substitution of wheat flour used in waffle ice cream cone making, since the sweet potato peel flour itself has dietary fiber, which are very suitable for 
diabetes and cancer patients as well as those individuals who are in a special diet in controlling obesity, high cholesterol level and body weight management. (Ware, 2019)

This study been carried out due to large amount of sweet potato peel waste found in the environment. As mentioned above, in 2011 there was about 7\% of sweet potato peel ended up as municipal solid waste. As we know, sweet potato peel contains nutritious value that is good for health. Therefore, in this study the sweet potato peels were being used as one of the ingredients in the waffle ice cream cone making in the form of sweet potato peel flour to reduce sweet potato peel waste production where annually there were $95 \%$ of by-products from vegetables are discarded during preparation and processing. (Marconato et al., 2020).

\section{Materials and Methods}

\subsection{Materials}

The sweet potato peels for making the sweet potato peel flour were collected from the stall operator in Sri Serdang, Selangor. Basic ingredients for waffle ice cream cone preparation (wheat flour, sugar, salt, egg, essence vanilla and evaporated milk) were purchased from a local supermarket.

Regarding to this study, the sweet potato peel flour has been added to the wheat flour at different formulations for the making of waffle cones. The sweet potato peel flour being prepared by drying and grinding process of sweet potato peel.

\subsection{Preparation of Sweet Potato Peel Flour}

The sweet potatoes were washed and separated into flesh and peel. To reduce the enzymatic browning, the peels were dipped into the $0.03 \%$ sodium metabisulphite solution for 30 minutes, drained and dried in an oven (Memmert Oven, at $65^{\circ} \mathrm{C}$ for 6 hours). The dried peels were grounded by using the Pensonic Blender (PB-802) (Power $=250$ Watt, Voltage $=220-240 \mathrm{~V}$ ), then it passed through $125 \mu \mathrm{m}$ sieve to extract sweet potato peel flour. Remaining of sweet potato peel flour was stored in an airtight plastic packs in room temperature for further analysis.

\subsection{Water Holding and Oil Holding Capacity (WHC and OHC)}

The method of determination of water and oil holding capacity is by centrifugation process was adapted from (Hussain \& Choudhry, 2014). One gram of sweet potato peel flour was balanced and placed into each centrifuge tubes. Then, $10 \mathrm{ml}$ of distilled water 
added into each centrifuge tubes. Then it was vortex for 30 minutes for uniform mixing. After standing at room temperature for 30 minutes, the samples were centrifuged for 25 min at $3000 \mathrm{xg}$. The sediments weighed after complete removal of the supernatant. The determination of oil holding capacity, $0.5 \mathrm{~g}$ samples homogenized with the canola oil (5 $\mathrm{ml}$ ) in the centrifuge tubes and proceeded further as described to determine the value of water holding capacity. All the sample done triplicate to get an average result. The WHC and $\mathrm{OHC}$ being calculated as below:

$$
\mathrm{WHC} \text { or } \mathrm{OHC}(\%)=\frac{\left(\mathrm{W}_{2-} \mathrm{W}_{1}\right)}{\mathrm{W}_{0}} \times 100
$$

where $\mathrm{W}_{0}$ is the weight of the sample, $\mathrm{W}_{1}$ is the weight of the centrifuge tube plus sample and $\mathrm{W}_{2}$ is the weight of the centrifuge tube plus sediments.

\subsection{Waffle Ice Cream Cone Preparation}

Formulations for the waffle cone is shown in Table 1. This formulation was synthesized from sorghum ice cream cone formulation (Kigozi et al., 2014). The basic waffle ice cream cone formula consisted of $100 \mathrm{~g}$ of wheat flour, $90 \mathrm{ml}$ of evaporated milk, $2 \mathrm{~g}$ of salt, $70 \mathrm{~g}$ of sugar, $3 \mathrm{ml}$ essence vanilla and 2 eggs. Three other waffle ice cream cone samples were prepared with the formulation of: (1) 5\% SPPF:95\% wheat flour; (2) 10\% SPPF:90\% wheat flour; and (3) 15\% SPPF:85\% wheat flour. The ready batter of control, 5\% SPPF, $10 \%$ SPPF and 15\% SPPF were placed to rest for a few minutes before baking. The batter for each formulation was poured on the waffle cone maker pan for 3.5 minutes at $150^{\circ} \mathrm{C}$. Each waffle was immediately folded into sharp cones after it has been removed from the pan. The cone shape waffle was properly stored in the vacuum plastics and placed in the container to prevent the texture of waffle cone from becoming less crispy due to the exposure to the air for further analysis.

Table 1. Formulation of waffle ice cream cone samples.

\begin{tabular}{ccccc}
\hline \multirow{2}{*}{ Ingredients $(\mathrm{g})$} & \multicolumn{4}{c}{ Formulation of waffle ice cream cones } \\
\cline { 2 - 5 } & Control & $\mathbf{5 \%}$ SPPF & $\mathbf{1 0 \%}$ SPPF & $\mathbf{1 5 \%}$ SPPF \\
\hline Wheat flour & 100 & 95 & 90 & 85 \\
Egg & 2 & 2 & 2 & 2 \\
Sugar & 70 & 70 & 70 & 70 \\
Salt & 2 & 2 & 2 & 2
\end{tabular}




\begin{tabular}{ccccc}
\hline \multirow{2}{*}{ Ingredients (g) } & \multicolumn{4}{c}{ Formulation of waffle ice cream cones } \\
\cline { 2 - 5 } & Control & $\mathbf{5 \%}$ SPPF & $\mathbf{1 0 \%}$ SPPF & $\mathbf{1 5 \%}$ SPPF \\
\hline Evaporated milk & 90 & 90 & 90 & 90 \\
Essence vanilla & 3 & 3 & 3 & 3 \\
Sweet potato peel flour (SPPF) & 0 & 5 & 10 & 15 \\
\hline
\end{tabular}

\subsection{Waffle Ice Cream Cone Texture Analysis}

Texture parameters of waffle cone were measured by TPA test using texture analyser (TA.XTplus Texture Analyzer, Stable Micro Systems, U.K) to measure the force required to cause breakage towards the waffle cone. The result of the textural profile generates for Exponent software. The probe used was the ice cream support rig (A/ICC). Measurements were carried out for the cone shape of waffle. Instrument settings were pulled to break mode: test speed $2 \mathrm{~mm} / \mathrm{s}$. Four texture parameters were determined: hardness, brittleness, toughness and crispiness. Three replicates of waffle cone from each formulation using sweet potato peel flour were determined.

\section{Results and Discussions}

\subsection{Proximate Analysis of Sweet Potato Peel Flour (SPPF)}

Table 2. Proximate analysis of flour.

\begin{tabular}{cccc}
\hline Parameter & $\begin{array}{c}\text { Orange-fleshed Sweet } \\
\text { potato peel flour (\%) }\end{array}$ & $\begin{array}{c}\text { Purple-fleshed Sweet } \\
\text { potato peel flour (\%) } \\
\text { (Marconato et al., 2020) }\end{array}$ & $\begin{array}{c}\text { Banana peel flour (\%) } \\
\text { (Zaleqha, 2019) }\end{array}$ \\
\hline Protein & 13.8 & 5.53 & 6.5 \\
Fat & 13.5 & 1.03 & 13.0 \\
Ash & 17.87 & 5.26 & 7.0 \\
Crude fiber & 3.99 & 12.76 & 16.6 \\
Moisture content & 8.56 & 4.32 & 8.9 \\
Carbohydrate & 47.38 & 71.09 & 71.0 \\
\hline
\end{tabular}

The result of proximate analysis (Table 2) among three types of peel flours, namely, orange-fleshed SPPF, purple-fleshed SPPF and banana peel flour shows that the orangefleshed sweet potato peel flour contained the highest amount of protein at $13.8 \%$, compared to purple-fleshed sweet potato peel flour at $5.53 \%$ and the banana peel flour at $6.5 \%$. Protein content is beneficial for the human body in helping to prevent the colon cancer, treating diabetes and help in controlling the weight of the body (Ware, 2019). 
However, this orange-fleshed sweet potato peel flour contains higher fat and ash content. Eating food with high amount of fat and ash is not healthy. Reducing the ash intake in the diet can help to minimize the urinary tract problems in the body. Besides, the sweet potato peel flour (SPPF) also contains crude fiber which is beneficial in treating and preventing the coronary heart disease and also some type of cancers. For both orange-fleshed sweet potato peel flour and banana peel flour, they consisted of high level in moisture content. Moisture content is very important in maintaining the shelf life of the products. The orange-fleshed sweet potato peel flour has the lowest carbohydrate content compared to the other types of peel-based flour. Low carbohydrate food is suitable for people who is on diet for different types of diseases and body weight management.

\subsection{Water and Oil Holding Capacity}

The moisture content of the flour must be less than $7 \%$ to make sure the flour to have a long shelf life and safe to be keep at room temperature (Ahmed et al., 2010). The water holding capacity for the sweet potato peel flour was $329.97 \%$, while for oil holding capacity was $295.94 \%$. From the result obtained from this study, the sweet potato peel flour retained water higher than the oil. The retention of sweet potato peel flour to oil correlated with the composition of protein with water and reaction of protein with other substances.

High water holding capacity flour is suitable for making viscous food products and also the meat-based products. The purple-fleshed sweet potato peel flour was used in making the hamburger (Marconato et al., 2020). Besides, the orange-peel sweet potato powder also used in the making of beef burger, which is the meat-based products (Mahmoud et al., 2017).

\section{$3.3 L^{*}, a^{*}$ and $b^{*}$ Colour of Waffle Ice Cream Cone}

Sweet potato peel waffle cones produced in this study were different from the commercial waffle ice cream cone in the industry today. The waffle folded into cone shape using cone shape fold. The waffle should be thin to make sure the texture produced was crispy and easier to be folded into a perfect cone shape. The control waffle cones produced were yellowish in colour, while the newly formulated waffle cones using different percentages of SPPF shows darker intensity of colour as the percentage of SPPF added increased to $15 \%$ making the appearance more attractive. 


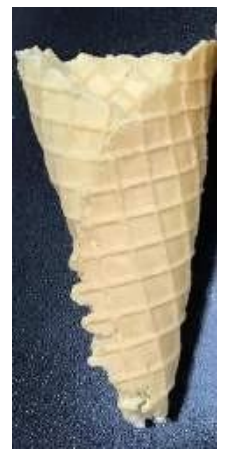

Figure 1. Control waffle cone.

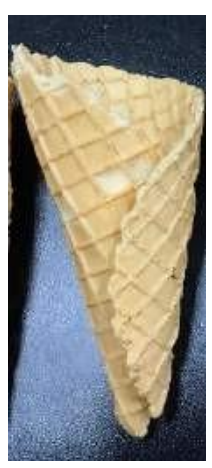

Figure 2. $5 \% \quad \mathrm{SPPF}$ waffle cone.

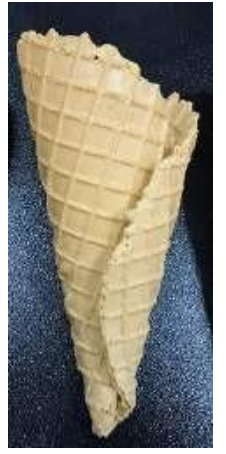

Figure 3. $10 \%$ SPPF waffle cone.

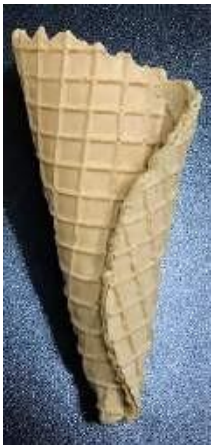

Figure 4. $15 \%$ SPPF waffle cone.

Colour is one of the most important factors and analysis in determining consumer acceptance of the respective food products. Colour characteristics of the waffle ice cream cone shown in Table 3. Based on the result obtained, it indicated that the colour of the control waffle ice cream cone had higher $\mathrm{L}^{*}$ value than waffle cone with substitution of sweet potato peel flour. The higher is the $\mathrm{L}^{*}$ value the lighter is the colour of the waffle cone, hence, it is highly correlated to Figure 1 indicating the colour of the waffle as yellow. The waffle ice cream cone with sweet potato peel flour appeared duller in colour compared to the control waffle ice cream cone. Dull in colour might be caused by dark in colour of the sweet potato peel flour. As the percentage of added SPPF increased, the lightness value declined, with $15 \%$ SPPF waffle cone was the darkest with the lowest $L^{*}$ value $(23.30 \pm 0.70)$, less red with the lowest $\mathrm{a}^{*}$ value $(9.03 \pm 0.60)$ and more yellow in color with the highest $b^{*}$ value $(31.77$ $\pm 3.07)$. The combination of colour characteristics of waffle ice cream cone resulted to either lightness or darker colour of the cones.

Table 3. Colour characteristics of waffle ice cream cone.

\begin{tabular}{cccc}
\hline Sample & $\mathbf{L}^{*}$ & $\mathbf{a}^{*}$ & $\mathbf{b}^{*}$ \\
\hline Control waffle cone & $27.57 \pm 0.15$ & $11.40 \pm 0.60$ & $29.80 \pm 6.33$ \\
$\mathbf{5 \%}$ SPPF waffle cone & $27.37 \pm 2.15$ & $16.97 \pm 9.39$ & $22.27 \pm 8.37$ \\
$\mathbf{1 0 \%}$ SPPF waffle cone & $24.07 \pm 0.59$ & $11.27 \pm 0.74$ & $29.60 \pm 6.46$ \\
$\mathbf{1 5 \%}$ SPPF waffle cone & $23.30 \pm 0.70$ & $9.03 \pm 0.60$ & $31.77 \pm 3.07$ \\
\hline
\end{tabular}

$\mathrm{L}^{*}$ indicates lightness, $\mathrm{a} *$ is the red/green coordinate, and $\mathrm{b}^{*}$ is the yellow/blue coordinate. 


\subsection{Texture Analysis of Waffle Cone}

Texture properties of the waffle cone is one of the important considerations in the making of waffle cone for the ice cream (Kigozi et al., 2016). The texture quality of the waffle is done in a cone shape (Huang et al., 1989). The texture characteristics of control waffle cone and with substitution of sweet potato peel flour were compared in Table 4. The parameters of waffle cone texture are focused on its hardness, brittleness, toughness and crispiness. From the result below, addition of sweet potato peel flour to the existing wheat flour ingredient at different formulation, $5 \%, 10 \%$ and $15 \%$, which resulted to higher value of hardness of the waffle cone compared to the controlled waffle cone, which only used the wheat flour. The substitution of $10 \%$ of sweet potato peel flour out of wheat flour amount into the formulation resulted the highest hardness of waffle cone (930.43 \pm 674.99$)$, followed by $5 \%$ SPPF waffle cone $(761.27 \pm 224.25)$ and $15 \%$ SPPF cone $(588.01 \pm 261.97)$. The less gelatinization occur in the batter resulted in the hardness of waffle cone texture (Kigozi et al., 2014). The four different batter formulations resulted to brittleness of the waffle ice cream cone within the same range, however, the lowest brittleness value was the $15 \%$ SPPF waffle cone followed by $10 \%$ SPPF cone. For the toughness result of the waffle cone, the substitution of sweet potato peel flour gave the higher value of toughness (i.e. $5 \%$ SPPF as the toughest followed by $10 \%$ SPPF and finally $15 \%$ SPPF waffle cones) compared to the controlled one. High in toughness value as per indicated by the value of 5\% and 10\% SPPF formulation in the waffle cone making, promotes safer handling, shipping and distribution of the cones as it can withstand with the certain value of pressure act on it. The value of crispiness of waffle cone obtained the highest result for the substitution of 5\% SPPF in the batter formulation and the least crispy of $10 \%$ SPPF waffle cone. 5\% sweet potato peel flour substitution of existing amount of wheat flour yielded ice cream waffle cone high in crispiness and brittleness. The properties might be due to the high composition of fiber in the sweet potato peel flour. High fiber content increase the texture of the waffle cone to become crispy, which then effect to the texture of the waffle cone.

Table 4. Texture characteristics of waffle cone.

\begin{tabular}{ccccc}
\hline Sample & Hardness & Brittleness & Toughness & Crispiness \\
\hline Control waffle cone & $341.17 \pm 89.87$ & $3.75 \pm 0.69$ & $366.60 \pm 63.30$ & $21.67 \pm 5.86$ \\
$\mathbf{5 \%}$ SPPF waffle cone & $761.27 \pm 224.25$ & $3.92 \pm 1.81$ & $856.46 \pm 565.79$ & $20.33 \pm 2.52$ \\
$\mathbf{1 0 \%}$ SPPF waffle cone & $930.43 \pm 674.99$ & $3.57 \pm 0.99$ & $855.26 \pm 962.03$ & $13.00 \pm 9.17$ \\
$\mathbf{1 5 \%}$ SPPF waffle cone & $588.01 \pm 261.97$ & $3.51 \pm 1.65$ & $506.59 \pm 157.11$ & $15.67 \pm 10.02$ \\
\hline
\end{tabular}


Further increasing the amount of sweet potato peel flour to be substituted to the wheat flour resulted in less crispiness of the waffle cone. This is due to the high water holding of the sweet potato peel flour, which can reached up to $329.97 \%$. The sweet potato peel flour retains the moisture of the batter, therefore when it was being cooked, the texture of the waffle was a bit moist and not crispy.

In the context of texture properties, 5\% SPPF waffle cone has yielded the best properties of second hardest, first in brittleness, the toughest and the crispiest compared to control waffle cone and other formulated SPPF waffle cones. Hence, 5\% SPPF waffle cone was the best and top in textural quality among the formulated waffle cones to be commercially produced in the factory and retain its shape during making, handling, shipping and distribution. For it to have the least water holding capacity among the newly formulated cones, makes it to have longer shelf-life as it remains dry after production and less likely to be infected by fungal growth.

Table 5. Texture characteristics of waffle cone using banana peel flour.

\begin{tabular}{cc}
\hline Sample & Crispiness \\
\hline Control waffle cone & 18.67 \\
$\mathbf{5 \%}$ waffle cone & 14.80 \\
10\% waffle cone & 17.67 \\
20\% waffle cone & 24.33 \\
\hline
\end{tabular}

Comparing the result of ice cream waffle cone from the banana peel flour, the $20 \%$ substitution of banana peel flour to replace a small percentage of wheat flour yielded the most crispiest waffle cone (Zanariah et al., 2019). This is due to the lower water holding capacity of banana peel flour, which was below than $5 \mathrm{~g} / \mathrm{g}$ (Bakar et al., 2018).

As the substitution of sweet potato peel flour have lower influence in the ice cream waffle cone making, it can be used for other applications due to its high water holding capacity. Substance with high water holding capacity can be applied as the water binding agent in meat processed food such as nuggets, sausages, meatballs, fish balls, beef and chicken patties and hamburgers. Besides, it also suitable in the making of bakery products as it could retain the moisture and improve its texture to make the end product more moist and fluffy. The application of sweet potato peel flour can be the same as corn flour as the corn flour is high in water holding capacity (Shad et al., 2013). It can be the binding agent for the 
food such as puddings which contain high moisture. These high water holding capacity also could be the thickener for the soups, stews and sauces.

Although the functional benefits of corn flour and sweet potato peel flour are similar, but both have different value of glycemic index. The corn flour has the glycemic index at 70 compared to sweet potato peel which have the value of 19. Food substance high in glycemic index value is not good for health as the food will be digested and absorbed into the bloodstream quickly and this cause large and rapid changes in the blood sugar levels. However, those with low glycemic index value such as sweet potato, should be applied in the food dietary intake for diabetic, obesity and cancer patients.

\section{Conclusion}

Based on the study, it is possible to produce waffle ice cream cone with the substitution of small percentage of wheat flour with at least $5 \%$ of sweet potato peel flour. In general, the addition of sweet potato peel flour to the existing wheat flour formulation has resulted to darker waffle ice cream proven with reduction in lightness value $\left(\mathrm{L}^{*}\right)$ cone, but still suitable in the making of waffle ice cream cone. Formulation of waffle cone batter using sweet potato peel flour had darker colour compared to the control waffle ice cream cone, which appeared bright yellowish colour. For textural properties, the waffle ice cream cone made from $10 \%$ and $15 \%$ sweet potato peel flour became less crispier than waffle ice cream cone made from $100 \%$ of wheat flour, but an exception for $5 \%$ SPPF waffle cones which are similar to the crispiness of control waffle cone. This is due high water holding capacity of sweet potato peel flour. Other than that, the sweet potato peel flour can be used for other food applications such as sweet potato puree making for baby food and other usage in food preparation, bakery products, beverages mixed with coffee or chocolate, making pudding, act as thickener or emulsifying agent to the soups and sauces and also suitable in making meat-based products.

Acknowledgments: Authors are thankful to the laboratory technicians, Department of Processing and Food Engineering, Faculty of Engineering, for their considerable help to complete this research successfully.

Funding: This research was financially supported by Universiti Putra Malaysia, Serdang, Selangor, Malaysia.

Conflicts of Interest: The authors declare no conflict of interest, and also the funders had no role in the design of the study; in the collection, analyses, or interpretation of data; in the writing of the manuscript, or in the decision to publish the results. 


\section{References}

Ahmed, M., Akter, M. S., \& Eun, J. B. (2010). Peeling, drying temperatures, and sulphite-treatment affect physicochemical properties and nutritional quality of sweet potato flour. Food Chemistry, 121(1), 112-118. https://doi.org/10.1016/j.foodchem.2009.12.015

Bakar, S. K. S. A., Ahmad, N., \& Jailani, F. (2018). chemical and functional properties of local banana peel flour. Journal of Food and Nutrition Research, 6(8), 492-496.

Food and Agricultural Organization (FAO). (2016). Retrieved from: http://faostat3. fao.org/home

Hashim, I., Syariffuddeen, A., Adnan, M., et al. (2019). Pembangunan sistem pengendalian dan pengawetan ubi keledek VitAto. Buletin Teknologi MARDI, 15, 49-64.

Huang, V. T., Luebbers, S. T., Lindamood, J. B., et al. (1989). Ice cream cone baking: 2. Textural characteristics of rolled sugar cones. Food Hydrocolloids, 3(1), 41-55. https://doi.org/10.1016/S0268-005X (89)80032-3.

Kigozi, J., Banadda, N., Byaruhanga, Y., et al. (2014). Optimization of texture in sorghum ice cream cone production using sensory analysis. The Open Food Science Journal, 8, 18-21. https://doi.org/10.2174/1874256401408010018

Kigozi, J., Banadda, N., Byaruhanga, Y., et al. (2016). Sorghum ice cream cone texture; correlations between instrumental and sensory analysis. Journal of Advances in Food Science and Technology, 3(3), 134145.

Mahmoud, M. H., Abou-Arab, A. A., \& Abu-Salem, F. M. (2017). Quality characteristics of beef burger as influenced by different levels of orange peel powder. American Journal of Food Technology, 12(4), 262-270. https://doi.org/10.3923/ajft.2017.262.270

Marconato, A. M., Hartmann, G. L., Santos, M. M. R., et al. (2020). Sweet potato peel flour in hamburger: Effect on physicochemical, technological and sensorial characteristics. Brazilian Journal of Food Technology, 23, 1-9. https://doi.org/10.1590/1981-6723.11519

Mohamad Zahari, N. I, Ahmad, S. M., \& Hassan, H. (2014). Penghasilan tepung pracampuran hasilan bakeri berasaskan ubi keledek VitAto (Development of premix flour for VitAto sweet potato based bakery products). Buletin Teknologi MARDI, 6, 9-16.

Mohd Hanim, A. B., Chin, N. L., \& Yusof, Y. A. (2014). Physico-chemical and flowability characteristics of a new variety of Malaysian sweet potato, VitAto flour. International Food Research Journal, 21(5), 2099-2107.

Shad, M. A., Nawaz, H., Noor, M., et al. (2013). Functional properties of maize flour and its blends with wheat flour: optimization of preparation conditions by response surface methodology. Pakistan Journal of Botany, 45(6), 2027-2035. https://doi.org/10.13140/2.1.4326.9760 
Ware, M. (2019). What's to know about sweet potatoes?. Retrieved from: Medical News Today https://www.medicalnewstoday.com/articles/281438

Zanariah, M. D., Nur Zaleqha, M. H., \& Lisnurjannah, M. (2019, March 21). Utilization of banana peel flour as fibre ingredient in the waffle cones. Konvensyen Kebangsaan Kejuruteraan Pertanian dan Makanan 2019, Wisma Tani, Kementerian Pertanian Malaysia, Putrajaya.

Copyright $(92020$ by Mohd Dom Z, et al. and HH Publisher. This work is licensed under the Creative Commons

Attribution-NonCommercial 4.0 International Lisence (CC-BY-NC4.0) 